\title{
Circular Economy and Strategic Risk ${ }^{*}$
}

\author{
Francesca Gennari ${ }^{* *}$, Raffaella Cassano ${ }^{* * *}$
}

\begin{abstract}
Governments and international organizations are focusing on resource consumption, both on the way resources are produced or extracted, and on the disposal of waste produced at the end of product lifecycle. At the same time, companies are called upon to rethink their business strategies and to adapt their management models, which need to be inspired by sustainable development.

In this sense, a systemic and integrated vision of the economic, social and environmental dimensions is essential to guarantee an effective corporate governance sustainability strategy. Furthermore, the change of business model towards the Circular Economy implies new challenges as managing the strategic risk in an integrated way. The aim of this article is to provide theoretical considerations about the transition from linear to circular economic model, in relation to the profound change of the company's core values and strategic risk.
\end{abstract}

Keywords: Strategic Risk; Vision and Core Values; Circular Economy; Sustainability Leadership; Stakeholder Relationship Management; Innovation

\section{Emerging Critical Issues}

The circular economy (CE) becomes the ideal transformation of the current economic model, since it proposes a total review of the economic-productive system throughout the life cycle of the outputs, from their design, to their realization, to consumption/use and to referral to other use.

The companies' ability to response to the global challenges becomes a key strategic asset, thanks to the rethinking of vision and corporate strategy in a way that benefits not only the company's survival itself, but also the future sustainability of the global economic, social and environmental system. Inevitably, this ongoing transformation contains considerable critical strategical and management aspects, which require new managerial skills. These aspects become fundamental for an effective company circularity, which is not only the observation of sporadic solutions for the recovery or containment of waste.

The corporate approach to sustainable value creation is a source of global competitive advantage (Brondoni, 2019). Sustainability, as a long-term vision, is part of the corporate strategy in socially responsible companies. It refers to a concept of global corporate responsibility (social, economic and environmental dimensions) and considers equally the interests of all those who contribute to the current and future

\footnotetext{
* The Authors: Gennari, F. $\S \S 4,4.1,4.2,4.3$, Cassano, R. $\S \S 1,2,3,5$.

** Associate Professor of Business Administration, University of Brescia (francesca.gennari@unibs.it).

*** Researcher of Business Administration, University of Brescia (raffaella.cassano@unibs.it)
} 
company's success (Miller \& Serafeim, 2014; Lee et al., 2016; Salvioni et al., 2018; Salvioni \& Gennari, 2019; Gennari 2019).

In order to provide theoretical considerations about the transition from linear to circular economic model, in relation to the profound change of the company's core values and strategic risk, the article outlines a framework on Circular Economy and Strategic Risk. First, starting from the relationship between corporate governance, sustainability and strategy, we affirm the relevance of the socially responsible vision, the development of integrated control systems and the culture of sustainability. This approach is fundamental to support the risk management into the entire strategic process based on the three fundamental pillars: strong governance (Governance Risk, $\S 4.1$ ), extensive relational networks (Stakeholder Relationship Management Risk, § 4.2) and high investments in innovation (Innovation Risk, § 4.3).

\section{Corporate Governance, Sustainability and Strategy}

Over the years, economic, social and technological progress has created the false belief that the growth and development of productive and commercial activities could be unlimited. Only since the 1970s, the world became aware of the limited availability of the planet's natural and economic resources. In those years, the researchers published the first studies about the relationship between environment and sustainable development (Andrews, 1971; Freeman, 1984). Towards the end of the last century, companies started to adopt actions aimed at transparency and inspired by a broad concept of responsibility, not only economic, but also social, environmental and sustainable one (Donaldson \& Preston, 1995; Salvioni, 2003).

The emergence of new paradigms of sustainable development oriented to the management of relations with stakeholders highlighted the interdependence between the stakeholder relationship management and corporate performance (Salvioni \& Gennari, 2017).

International policies aimed at strengthening and developing corporate social responsibility in corporate decisions and actions are intensifying: the concept of social responsibility evolves to a global vision of the company and becomes a deep strategic orientation towards sustainable systemic development (Miles, 2012; Cassano, 2019).

The concept of corporate social responsibility and sustainability is based on good corporate governance, synonymous of fairness of interests, transparency of information and behavior, stakeholder responsibilities and governance commitment. All these principles are closely linked to the prerogatives of the board of directors that, if inspired by sustainable strategies, determines a governance approach aimed at the growth of corporate value in the long term.

In this sense, the role of the board as a guide for the entire organization becomes fundamental. Sustainability-oriented leadership requires CSR to be transferred from top management to the rest of the workforce, spreading a true culture of sustainability throughout the organization (Painter-Morland, 2006). According to this vision, sustainable development strategic approach disregards the various corporate governance systems. Therefore, it become a unique factor of substantial convergence for a sustainable development of the company's growth conditions, and it ensures the 
future prosperity of the economic, social and environmental system (circular economy and corporate strategy).

Companies that want to be leaders in sustainability need to address the profound change in their vision and permeates it into the corporate strategy, accentuating the central role of the sustainability culture of corporate governance bodies as promoters and guarantors of the effectiveness of the change itself (Carroll, 1999; Dahlsrud, 2008; Jo \& Harjoto, 2012; Gandini et al. 2014).

Therefore, the members of the board of directors are the most important actors in the process of achieving sustainability leadership. In this sense, we can say that the strength of leadership starts at board level: executive members of the board must recognize the principles of sustainability, sharing these principles with non-executive members and transferring them to the long-term direction of the organization. This process depends on the basic principles that characterize the corporate culture.

Therefore, thanks to the commitment of leaders, the CE implies changes mainly due to:

- the appreciation of a socially responsible vision of governance, based on effective stakeholder engagement processes, the creation of integrated relational networks, the generation of innovative solutions with important strategic investments;

- the development of integrated control systems in the evolution of the objectives which allows the risks monitoring in relation to the various dimensions of responsibility for the detection of strategic risks;

- the change of the variables to be monitored, with a greater appreciation of the culture of sustainability and critical factors for the optimization of relations with stakeholders and with the environment.

Only if there is a deep strategic orientation of the entire organization to the sustainability culture, in a systemic and integrated CSR perspective, the approach for a circular business model is possible. Otherwise, we can only talk about actions or projects characterized by responsible behavior or processes to contain the waste generated by the company's production/logistic cycle.

\section{From Linear to Circular Economy: The Vision is Strategic}

$\square$ «Back in 1989, we had a big, crazy idea. What if we could turn
greenhouse gases like carbon dioxide into products? We got to
work, looking to plants for inspiration. It took a lot of hard thinking
and some real innovation, but today Ingeo polymers are valued for
their unique properties and found in products from coffee capsules
to electronics (NatureWorks - Ingeo). At NatureWorks, we use our
best technologies to turn greenhouse gases, like carbon dioxide,
into performance materials. The sustainability of how we convert
these greenhouse gases into Ingeo and Vercet products matters,
and we take a hard look at this in everything we do. Currently, the
first step in transforming greenhouse gases into our products
involves using agricultural crops to sequester carbon, "fixing” it
as simple plant sugars through the process of photosynthesis.»




\begin{abstract}
«While we view carbon as a problem, nature views it as a resource and an essential building block.» (Bryony Schwan, The BioMimicry Institute).
\end{abstract}

The way is found, if you have first glimpsed where you want to go.

In this sense, it can be argued that the vision is strategic. Proper business management and success of a business depend by the definition of the vision, the mission and core values. Define a circular-oriented vision means having clear the core sustainability goals, which lead the decision-making processes and actions.

The vision defines the company's projection into the future outlining the development horizons and the growth of the company, according to the general trends of the economic, environmental and social system. It is deeply influenced by the values, aspirations, ideals and ambitions that distinguish those who rule the company.

Setting your vision with precision over time allows you to carry out accurately business analysis with respect of:

- the timing of the progressive growth steps that the company must consider in order to achieve its vision;

- the essential elements for achieving the objectives;

- the activities to be carried out and the networks to be consolidated in order to ensure optimum conditions for the development of its activity.

The transition to a circular model implies a profound redefinition of the company's vision. Therefore, the vision permeates strategy.

Similarly, the mission, although not changing in the transition to the circular model, is reinterpreted in the light of the new vision and acquires a greater strength for allowing the company to translate its core values into measurable actions and results.

As stated in the previous Section, the transformation of the business model according to a circular perspective cannot be limited to an action or a company's project. It represents a profound transformation of the corporate strategy and therefore redefines the corporate vision and emphasizes the value of the mission.

The internal balances of the entire organization are modified, starting from the corporate governance and control bodies, to the redefinition of the corporate value chain.

From linear to circular model, the company's core values change profoundly. In particular, the corporate culture seeks new ways of expression through the definition of new paths, alternative and sustainable to those implemented until a given moment, with the intention of achieving a new vision of the company. This is in line with what it is imposed by the survival conditions of the economic, social and environmental system.

Only through this internal growth, the company can effectively defines its development process and aim to obtaining optimal corporate performance.

A circular strategic approach requires a strong focus on three fundamental pillars:

- presence of strong governance, oriented towards transparency and sharing of its corporate strategies and choices, as well as having high adaptive and experimental capabilities;

- building strong and extensive relational networks;

- high investments in innovation for the study of alternative solutions to current / linear conditions. 
The construction of strong relational networks identifies the fundamental strategic asset for the development of new business opportunities or the creation of better and optimal virtuous economic circles. In the same way, research and innovation activities and belonging to relational networks represent a fundamental and strategic assets for achieving the corporate vision. In fact, they represent the essential conditions to find new and alternative growth solutions.

Necessarily, the transition to a circular model highlights both many critical issues and exposure to new or unexpected corporate risks. Among others, this article, keeping the attention on the critical issues in corporate governance, reflects on the strategic risk associated with the transition from a linear to a circular business model (Table 1).

Table 1: From Linear to Circular Economy: The Effects of a New Corporate Vision

\begin{tabular}{|l|l|l|l|l|}
\hline $\begin{array}{l}\text { Economic } \\
\text { Model }\end{array}$ & Context & Opportunities & Focus & Effects \\
\hline Linear model & $\begin{array}{l}\text { Conditions } \\
\text { limited to } \\
\text { relations } \\
\text { established } \\
\text { between a few } \\
\text { and defined } \\
\text { partners }\end{array}$ & $\begin{array}{l}\text { Opportunities } \\
\text { defined by the } \\
\text { classic business } \\
\text { model }\end{array}$ & $\begin{array}{l}\text { Resource } \\
\text { Life } \\
\text { Cycle: } \\
\text { take, } \\
\text { make, } \\
\text { dispose }\end{array}$ & $\begin{array}{l}\text { Excessive } \\
\text { consumerism without } \\
\text { control that produces } \\
\text { masses of waste } \\
\text { harmful to the global } \\
\text { system }\end{array}$ \\
\hline Circular model & $\begin{array}{l}\text { It acts in an } \\
\text { interrelated and } \\
\text { integrated } \\
\text { system where } \\
\text { the opportunities } \\
\text { are also the } \\
\text { indirect effect of } \\
\text { relationships } \\
\text { between } \\
\text { partners. }\end{array}$ & $\begin{array}{l}\text { Opportunities arise } \\
\text { in the areas of } \\
\text { sustainability } \\
\text { (social, economic, } \\
\text { environmental) } \\
\text { with the possibility } \\
\text { of triggering new } \\
\text { businesses }\end{array}$ & $\begin{array}{l}\text { Resource } \\
\text { Life } \\
\text { Cycle: } \\
\text { produce, } \\
\text { consume, } \\
\text { reuse }\end{array}$ & $\begin{array}{l}\text { Ability to capture the } \\
\text { needs of the social and } \\
\text { environmental system } \\
\text { and transfuse them into } \\
\text { solutions that can make } \\
\text { the best use of } \\
\text { resources, rethinking } \\
\text { them for different uses }\end{array}$ \\
\hline
\end{tabular}

\section{Circular Economy and Strategic Risk}

The path toward the awareness of $\mathrm{CE}$ as a future strategic goal for competitiveness in global markets (Salvioni \& Gennari, 2014) implies a deep capability to manage risks related to the adjustment of the corporate business.

Strategy refers to a complex decision-making process, which from mission, vision and core values drives all the future choices to be competitive in global markets. The increasing importance of the connection between strategy and corporate performance implies a deep consideration of strategic risk that is the possibility that events will occur and affect the achievement of CE strategies and related business objectives (COSO, 2017). In other words, the path from a linear to a circular vision requires a deep consideration about the risk related to the future and to what the company will do inside this future. Strategic risk can disrupt a company's ability to accomplish its goals and achieve value for itself and its stakeholders. Hence, leaders embrace strategic risk management that is the process of recognizing risks coming from 
outside or inside, identifying their causes and effects, and taking the relevant actions to mitigate them to avoid potential obstacles to success and maximize corporate performance.

According to a dynamic concept of strategy as depicted by Mintzberg (Mintzberg $\&$ Waters, 1985) risk refers also to opportunities, which can arise because of uncertainty. Therefore, events that are negative in the achievement of some goals, can pose a challenge for the value creation associated to other objectives.

The existing literature emphasizes this integrated risk-focused approach to strategy (Louche et al., 2010; Anderson \& Frigo, 2017) which needs the support by board because of the board is the depository of the risk-aware corporate culture, having a broad view on the entire organization and its goals for creating value in the long run.

According with the previous considerations, organizations involved in $\mathrm{CE}$ strategies should integrate risk management into the entire process that includes the planning, the assessment and the achievement of strategies (COSO, 2017), based on the three key CE pillars as depicted in Section 3. This to balance the long-term view on social and environmental outcomes with the short-term pressures for financial performance. The loop closes itself with the identification of possible actions for the identified risk response. In case of strategies failures the process needs to be retraced for the identification of gaps and related causes.

\subsection{Circular Economy Strategies and Governance Risk}

Circular economy strategies are the results of corporate boards strongly oriented to sustainability, innovation and resiliency. This commitment by boards drives the planning stage that is the strategy's formalization according with mission, vision and corporate core values, namely the boundaries within strategies, and related actions, should be issued to guarantee a coherence among the entity's aims, decisions, actions and communication toward stakeholders.

Scholars emphasize the importance to consider CE strategies by a holistic approach (Korhonen et al., 2017) around the sustainability value drivers (increasing resource efficiency, extending lifespan, and closing the loop) in order to reduce the risk caused by a strategy not aligned with mission, vision, and core values (Despeisse et al., 2017; Bressanelli et al., 2018).

This governance risk is related to the board's ability of formulating CE strategies considering the board structure, responsibility and accountability.

Board structure has been extensively studied as a factor determining a higher or lower corporate orientation to sustainability (Zhang et al., 2013; Gennari \& Salvioni, 2019). The establishment of committees devoted to sustainability issues, the number of non-executive and independent members, and the separation between CEO and Chairman are mechanisms to protect stakeholders in order to reduce the risk that short-term orientation prevails on long-term value creation. For this reason, the board needs to evaluate itself in terms of composition, nomination and remuneration policies to guarantee that stakeholder requirements are adequately considered.

The alignment between corporate strategies and global expectations is emphasized also by international regulators that, with targeted actions on specific industries (e.g. textiles, plastics, packaging, electronics), are pressing for global competitiveness while protecting the environment and giving new rights to consumers (European Commission, 2020). 
Furthermore, CE strategies require special directors' skills and sensitivity because of the technical complexity of circular projects and their difficulty to be assessed in terms of future benefits. In this case, potential trade-offs between alternative circular and not circular strategies can arise, emphasizing the ability by board to assess properly the equilibrium between current efforts and future performance.

Furthermore, the board is responsible and accountable to stakeholders being clear about the expectations and cultivating long-term relations with them. CE philosophy finds a real implementation in corporate strategies only with the engagement of the entire value chain: to close the loop all entities, from regulators and resources suppliers to final consumers, play an essential role. Moving to a circular model implies a radical change, which requires a new way of thinking, doing business and using and consuming goods and services. In other words, board takes the responsibility for changing the traditional business model or for introducing a completely new one.

$\square$ Teemill is a tech-based fashion business [...]. The company began as a fashion brand, but after working many years to design a circular supply chain, they re-launched Teemill as a platform in 2018. The new company, a software platform for all fashion brands, makes the proprietary real-time manufacturing technology and circular model accessible to anyone with an internet connection that wants to sell branded garments. Tens of thousands of startups, charities, and even former competitors now use this technology for their fulfilment, allowing them to replicate the benefits and make a profit.

Business model defines the way a firm does business, translating strategy into value. It depicts the value proposition, the resources as core competencies and assets, and the network to transfer the value created to markets. Board, by means of the formal definition of $\mathrm{CE}$ business models, can provide a framework for identifying key risks with the awareness that $\mathrm{CE}$ requires the consideration of outcomes, other than outputs, and a more complex system of actors taking part in the strategy achievement. When these changes are underestimated and a short-term view by board prevails, circular business models are assessed as unacceptable.

\subsection{Circular Economy Strategies and Stakeholder Relationship Management Risk}

When evaluating alternative strategies, the board seeks to identify and understand the potential risks of each one. In general, strategies assessment focuses on their critical assumptions considering the current and potential relations with external and internal stakeholders depending on the performance strategies are able to achieve.

All the process of strategy assessment revolves around the concept of corporate performance. Even if there is no commonly accepted definition of CE, it is recognized that this concept is a dimension of the principle of sustainable development (Taylor, 2016; Kirchherr et al., 2017). Hence, all considerations about the evaluation of CE strategies by board is based on this wide concept of performance 
for different stakeholders and on company's responsibility to avoid the risk that the entire assessment process is misinterpreted.

The acceptability of CE strategies refers to their ability to satisfy stakeholders' expectations considering the defined threshold of tolerable risk. Companies establish a variety of relations with numerous categories of stakeholders, each of which declares or implicitly brings different expectations and suffers the gap of suboptimized performance. The search for an equilibrium among these expectations can be found positioning stakeholders into a map, which, considering the importance of the issues related to $\mathrm{CE}$ projects for them and the company according with the concept of materiality, highlights the priorities in a comparative view. In this step of strategy assessment, the risk of giving too much importance to special stakeholder categories or short-term expectations must be taken into account.

The establishment of effective relations with stakeholders and the assessment of related risks find ground within a framework representing the external context and the internal capabilities. Many relations suffer from external constraints and internal weaknesses, as well as they can benefit from external opportunities and internal strengths.

The macro-environment looks as a breeding ground for CE corporate strategies. International and national regulators are actively engaged in fostering companies' actions towards the global goals for a more sustainable world declared with the 2030 Agenda (as the Circular Economy Action Plan by EU and the public resources made available from national governments according with the Green New Deal).

Added to this, the society and consumers are more and more awareness about the global problems related to the current path of development characterized by the use of linear economy and press for having more power in the so-called on-demand economy.

In addition, the competitive environment as a whole is focusing on sustainability as a critical success factor. A KPMG International's research revealed that more than one-third of C-suite and board members indicated that investors' pressure had increased their company's focus on ESG (environmental, social and governance) issues (KPMG, 2019).

\section{$\square$ In recent years, businesses have witnessed an increased effort on the part of regulators to curtail and price negative externalities. Since 2009, the number of climate change laws has increased by 66\%, from 300 to 500. (Ellen MacArthur Foundation, 2015)}

Within this context, companies have to formulate strategies that guarantee a sustainable competitive advantage in the long-run by using existing distinctive resources. When $\mathrm{CE}$ is assessed as a good strategy because of its suitability with external environment and with stakeholders populating this environment, a careful analysis on the ability to internally sustain this strategy follows.

Internal resources, construed as physical goods, income and financial issues, but also as intangible assets incorporated into the value chain as human resources with their skills, abilities, and relations are arranged within the organization to optimize their synergies, considering the long period characterizing the return of $\mathrm{CE}$ investments and the difficulty to estimate social and environmental outcomes. 
$\square$ «Transformative change does not come from a void. It requires knowledge, skills and action. Today, however, little attention is put on how skills, company dynamics, accounting and other work practices can become more sustainable. Managers are central in shaping the strategic development of their companies while ensuring that all business parameters align to the objectives.» $(L$. Ramme and J.P.Steeger, the President and the Policy and Communication Officer of CEC European Managers).

\subsection{Circular Economy Strategies and Innovation Risk}

The achievement within the organization of the CE strategies needs the support of internal control mechanisms that assure the strategic aims are managed according with a holistic corporate view. In fact, the shift to circular business models is characterized by investments in innovation for alternative solutions to linear model, which generate true negative cash flows in the present and unclear positive cash flows in the future. For this reason, a CE strategy assessed as achievable by the board requires to be turned into operational objectives with the awareness of a time gap between current efforts and future benefits.

The financial sector has a pivotal role in supporting the companies' innovation process toward the $\mathrm{CE}$ by means of an investment strategy oriented to the long term which, in the assessment of organisations, integrates the financial analysis with the social, environmental and governance ones.

$\square$ Sustainable responsible investments grew up of 34\% in 20162018, compared with the $25.2 \%$ in the previous two years (GSIA, 2018). European Union keeps the leading position in the way for a sustainable and circular economy. The European Investment Bank (EIB) has provided about EUR 2.1 billion in co-financing for circular economy projects over the last five years, but the lending needs and potential of the circular economy transition are clearly much larger (EIB, 2018). For this reason EIB with the EU largest national banks and institutions are ready to invest at least EUR 10 billion in the circular economy by 2023. (EIB, 2020)

The time gap and the ESG (environmental, social and governance) evaluation criteria impose a correct timing in the assessment of the investments achievement and a correct choice of related performance indicators. The risk that current pressures, caused by contingent facts or disaster events as sanitary emergence, interrupt a sustainability path is real. Hence, also the realization of CE strategies is approached according to the risk management.

The current approach to entire internal control system revolves around the corporate risk, emphasizing the importance of integration with the enterprise risk management (COSO, 2013). Therefore, when the board has decided upon the strategies, which are relevant for a circular way to do business, the next step is to verify the appropriateness of the internal control system, starting from the management control in order to define the responsibilities, the expected results and the related risks potentially affecting the processes. 
In particular, the pillars at the basis of CE-focused management control are the spread of the circular values and motivation by employees to adhere to circular principles, the cascade of strategic planning goals into targets, action plans and performance measurements, with a higher attention for the product life cycle (from cradle-to-cradle) and for new key performance indicators (Svensson \& Funck, 2017).

CE strategies, being longer time oriented and not always consistent with economic gain in the short run (Kircherr et al., 2017), require adjustments in the assessment of operational decision-making processes and related targets, stressing the areas of cost accounting and investments budgets.

Hence, organizations should be aware that $\mathrm{CE}$ implies a new perspective to run the business; the adoption of CE strategies without this change of vision can nurture the risk of a misalignment between new critical success factors and conventional key performance indicators. Furthermore, targets themselves can facilitate the transition towards CE when they are correctly identified (Morseletto, 2020) because their achievement supports the strategy soundness.

The assessment of CE investments by board and management benefits from the effectiveness of information systems. Internal control processes are based on the information flows between governance bodies and organization.

New IT generate an exponential growth in the volume of data and the possibility to store and easily process them. In this context, the risk of information overload can rise leading to wrong decisions by both company and its stakeholders. The challenge for risk managers is in extracting meaningful and actionable information from a sea of seemingly unstructured data.

Hence, the maintenance of a high level of quality in internal information is essential for a correct formulation, assessment and achievement of CE strategies, as well a high level of quality in external information is essential for the development and maintenance of positive relations with stakeholders.

The standard BSI 8001:2017 about transparency remarks that organizations are open about decisions and activities that affect their ability to transition towards a more circular and sustainable mode of operation and are willing to communicate these in a clear, accurate, timely, honest and complete manner. Also, the Committee of Sponsoring Organizations of the Treadway Commission (COSO, 2013) remarks as information is one of the components of the internal control system and it assumes a pivotal role also for external stakeholders.

\section{Final Considerations and Emerging Issues}

Since the 1960s, scholars and international bodies have emphasized the relationship between corporate governance and corporate social responsibility, highlighting the importance of socially responsible governance to support corporate value creation over time. The integration between leaders' decisions and day-by-day activities is the way to promote a true CSR culture throughout the organization, ensuring consistency between the board strategies, organization's values and day-by-day practices. These 
premises represent, in the current context, the essential business condition to adopt in order to implement the transition to a circular economic model.

Board of directors has the responsibility to lead the transition from linear model, mostly focused on the optimization of economic performance, to circular model, where the interdependence between economic, social and environmental dimensions is the focus for the development of all business decision-making and governance processes.

The change towards a circular perspective cannot be limited to an action or a company's project. It represents a profound transformation of the corporate strategy, embracing a real culture of sustainability, starting from the redefinition of the corporate vision and emphasizes the value of the mission according to a risk-focused approach.

CE strategies force companies to become aware of the uncertainty, and therefore of how much risk they are willing to accept. In fact, circular choices require a new approach to business, because of the deep innovation in products and processes, the rethinking of corporate value chain, the establishment of new resources policies with suppliers and clients, and the recognition of the value created by consumers. In addition, circular issues are changing the macro-environment (societal expectations, policy makers' rules, technological development, etc.) creating a dynamic landscape in which companies have to move.

Hence, considerations about $\mathrm{CE}$ find a support on the strategic risk associated to the presence of a governance oriented to transparency and with adaptive and experimental capabilities, to strong and extensive networks, and to high investments in innovation. The adoption of a holistic approach anchored to risk management is the key to switch from $\mathrm{CE}$ pilot projects or $\mathrm{CE}$ occasional experiences to a circular culture within all the organization.

\section{Bibliography}

Anderson, R. J., \& Frigo, M. L. (2017). Assessing and Managing Strategic Risks: What, Why, How for Internal Auditors. Austria: Institute of Internal Auditors Foundation.

Andrews, K. R. (1971). The concept of Corporate Strategy. Illinois: Irwin, Homewood.

Bressanelli, G., Adrodegari, F., Perona, M., \& Saccani, N. (2018). Exploring How Usage-Focused Business Models Enable Circular Economy through Digital Technologies. Sustainability, 10(3), 639. http://dx.doi.org/10.3390/su10030639

Brondoni. S. M. (2019). 4.0 IR, Oversize Economy and the Extinction of Mammoth Companies. Symphonya. Emerging Issues in Management (symphonya.unicusano.it), (2), 8-24.

http://dx.doi.org/10.4468/2019.2.02brondoni

Carroll, A. B. (1999). Corporate Social Responsibility: Evolution of a Definitional Construct. Business \& Society, 38(3), 268-295.

http://dx.doi.org/10.1177/000765039903800303

Cassano, R. (2019). Corporate Global Responsibility and Reputation Risk Management. Symphonya. Emerging Issues in Management (symphonya.unicusano.it), (1), 129-142.

http://dx.doi.org/10.4468/2019.1.10cassano

COSO (2013). Internal Control - Integrated Framework.

https://www.coso.org/Documents/990025P-Executive-Summary-final-may20.pdf 
COSO (2017). Enterprise Risk Management. Integrating with Strategy and Performance.

https://www.coso.org/Documents/2017-COSO-ERM-Integrating-with-Strategy-and-PerformanceExecutive-Summary.pdf

Dahlsrud, A. (2008). How Corporate Social Responsibility Is Defined: An Analysis of 37 Definitions. Corporate Social Responsibility and Environmental Management, 15(1), 1-13.

http://dx.doi.org/10.1002/csr.132

Donaldson, T., \& Preston, L. (1995). The Stakeholder Theory of the Corporation: Concepts, Evidence, and Implementation. Academy of Management Review, 20(1), 65-91.

Driscoll, D. (2001). Ethics and Corporate Governance: Lessons Learned from a Financial Services Model. Business Ethics Quarterly, 11(1), 145-158.

Ellen MacArthur Foundation (2015). Towards a Circular Economy: Business Rationale for an Accelerated Transition.

www.ellenmacarthurfoundation.org/publications/towards-a-circular-economy-business-rationalefor-an-accelerated-transition

European Commission (2020). Circular Economy Action Plan.

https://ec.europa.eu/environment/circular-conomy/pdf/new_circular_economy_action_plan.pdf

European Investment Bank (2018). The EIB in the circular economy.

https://www.eib.org/attachments/thematic/circular_economy_en.pdf

European Investment Bank (2020). Circular Economy Overview 2020.

https://www.eib.org/attachments/thematic/circular_economy_overview_2020_en.pdf

Freeman, R.E. (1984). Strategic management: A stakeholder approach. Boston: Pitman.

Gandini, G., Gennari, F., Cassano, R. (2014). Global Responsibility and Strategic Risk Management, Journal of Business Management and Applied Economics, 3(5), 1-15.

Gennari, F. (2019). How to Lead the Board of Directors to a Sustainable Development of Business with the CSR Committees. Sustainability, 11(24), 6987.

http://dx.doi.org/10.3390/su11246987

Gennari, F., \& Salvioni, D. M. (2019). CSR Committees on Boards: The Impact of the External Country Level Factors. Journal of management and Governance, 23, 759-785.

http://dx.doi.org/10.1007/s10997-018-9442-8

Global Sustainable Investment Alliance (2018). Global Sustainable Investment Review.

http://www.gsi-alliance.org/wp-content/uploads/2019/03/GSIR_Review2018.3.28.pdf

Jo, H., \& Harjoto, M. A. (2012). The Causal Effect of Corporate Governance on Corporate Social Responsibility. Journal of business ethics, 106(1), 53-72.

http://dx.doi.org/10.1007/s10551-011-1052-1

Kirchherr, J., Reike, D., \& Hekkert, M. (2017). Conceptualizing the Circular Economy: An Analysis of 114 Definitions. Resources, Conservation \& Recycling, 127, 221.232.

http://dx.doi.org/10.1016/j.resconrec.2017.09.005

Korhonen, J., Nuur C., Feldmann A., \& Birkie, S. E. (2018). Circular Economy as an Essentially Contested Concept, Journal of Cleaner Production, 175, 544-552.

http://dx.doi.org/10.1016/j.jclepro.2017.12.111

KPMG (2019). Frontiers in Finance.

https://assets.kpmg/content/dam/kpmg/xx/pdf/2019/03/frontiers-in-finance-2019.pdf

Lee, J.S., Kim, S.K., \& Lee, S.-Y. (2016). Sustainable Supply Chain Capabilities: Accumulation, Strategic Types and Performance. Sustainability, 8, 503.

http://dx.doi.org/10.3390/su8060503

Louche, C., Idowu, S., \& Filho, W. (2010). Innovative CSR: From Risk Management to Value Creation. New York: Routledge. 
Miles, S. (2012), Stakeholders: Essentially Contested or Just Confused? Journal of Business Ethics, 108(3), 285-298.

http://dx.doi.org/10.1007/s10551-011-1090-8

Miller, K., \& Serafeim, G. (2014). Leading Sustainable Change. Oxford, UK: Oxford University Press.

Mintzberg, H., \& Waters, J. A. (1985). Of Strategies, Deliberate and Emergent. Strategic Management Journal, 6(3), 257-272.

http://dx.doi.org/10.1007/978-1-349-20317-8_1

Morseletto, P. (2020). Targets for a Circular Economy. Resources. Conservation \& Recycling, 153, 104553.

http://dx.doi.org/10.1016/j.resconrec.2019.104553

Painter-Morland, M. (2006). Triple Bottom-Line Reporting as Social Grammar: Integrating Corporate Social Responsibility and Corporate Codes of Conduct. Business Ethics. A European Review, 15(4), 352-364.

http://dx.doi.org/10.1111/j.1467-8608.2006.00457.x

Salvioni, D. M. (2003). Corporate Governance and Global Responsibility. Symphonya. Emerging Issues in Management (symphonya.unimib.it), (1), 44-54.

http://dx.doi.org/10.4468/2003.1.05salvioni

Salvioni, D. M., \& Gennari, F. (2014). Corporate Governance, Sustainability and Capital Markets Orientation. International Journal of Management and Sustainability, 3(8), 469-483.

Salvioni, D. M., \& Gennari, F. (2017). CSR, Sustainable Value Creation and Shareholder Relations. Symphonya. Emerging Issues in Management (symphonya.unimib.it), (1), 36-49.

http://dx.doi.org/10.4468/2017.1.04salvioni.gennari

Salvioni, D. M., Franzoni, S., Gennari, F., \& Cassano, R. (2018). Convergence in Corporate Governance Systems and Sustainability Culture. International Journal of Business Performance Management, 19(1), 7-15.

http://dx.doi.org/10.1504/IJBPM.2018.088490

Salvioni, D. M., \& Gennari, F. (2019). CSR, Sustainable Value Creation and Shareholder Relations. Symphonya. Emerging Issues in Management (symphonya.unicusano.it), (1), 28-39.

http://dx.doi.org/10.4468/2017.1.04salvioni.gennari

Svensson, N., \& Funck, E. K. (2017). Management Control in Circular Economy. Exploring and Theorizing the Adaptation of Management Control to Circular Business Models. Journal of Cleaner Production, 2331, 390-398.

http://dx.doi.org/10.1016/j.jclepro.2019.06.089

Taylor, S. J. (2016). A Review of Sustainable Development Principles.

http://mri.scnatweb.ch/en/afromontcontent/afromont-discussion-documents/2602-sustainabledevelopment-review-2016/file

Zhang, J. Q., Zhu, H., \& Ding, H. (2013). Board Composition and Corporate Social Responsibility: An Empirical Investigation in the Post Sarbanes-Oxley Era. Journal of Business Ethics, 114(3), 381-392. http://dx.doi.org/10.1007/s10551-012-1352-0 